\title{
PERAN INTERVENSI GRUP PSIKOTERAPI SUPORTIF UNTUK MEMPERBAIKI KEADAAN DEPRESI PADA WANITA INFERTIL DI KLINIK PERMATA HATI RSUP DR. SARDJITO YOGYAKARTA
}

\author{
Mega Dhestiana ${ }^{1}$, Carla Marchira², Rukmono Siswishanto ${ }^{3}$, Shofwal Widad ${ }^{4}$
}

\begin{abstract}
Background: Infertility is a worldwide problem, relates to a devastating condition that can destroy couples striving to have children. It can affect both men and women, and cause psychological related distress, depression, and low self--esteem. Most interventions using directional, complete, and integrated approach have been focused on improving the quality of life of infertile men or women. Supportive psychotherapy is an example of such interventions.

Objective: The study aimed to measure the effectiveness of supportive psychotherapy intervention in treating depression among infertile women.

Method: A quasi experiment design using a pre and post--test with a control group was employed in this study. Subjects were women $(n=80)$ with infertility cases who sought for treatment at PermataHati Clinic Dr. Sardjito hospital. during the period from April to September 2014. A modified short supportive psychotherapywas to groups of patients over the course of four sessions. The sessions were managed by trained facilitatorscomprising psychiatrist and psychologist. Personal data and Beck Depression Inventory (BDI)were then used to assess the patients depression state.

Result and Discussion: Findings indicated that $59.37 \%$ of the study subjects were found to have mild depression, whereas the other $40.63 \%$ had moderate depression. A significant change in BDI scores within the treatment group was found after intervention.

Conclusion:Modified short supportive psychotherapy intervention can effectivelly reduce depression on infertile women.
\end{abstract}

Keywords: modified short supportive psychotherapy, depression, infertile women

\begin{abstract}
ABSTRAK
Latar Belakang: Infertilitas merupakan masalah global yang berhubungan dengan kondisi-kondisi yang membuat pasangan sulit memperoleh keturunan. Masalah ini dapat mengenai pria dan wanita dan menimbulkan stres psikologis, depresi dan self-esteem rendah. Kebanyakan intervensi menggunakan pendekatan direksional, lengkap dan terpadu yang ditujukan untuk memperbaiki kualitas hidup pasangan. Psikoterapi suportif merupakan salah satu contoh intervensi.

Tujuan: Penelitian ini bertujuan mengukur keefektifan psikoterapi suportif dalam mengatasi depresi pada wanita infertil.

Metode:Rancangan penelitian ini adalah kuasi eksperimen, pre dan postes dengan kelompok kontrol. Subjek adalah wanita infertil $(n=80)$ yang berobat ke Klinik Permata Hati RSUP Dr. Sardjito selama April hingga September 2014. Modifikasi psikoterapi suportif diberikan pada kelompok intervensi sebanyak empat sesi yang dilakukan oleh fasilitator terlatih terdiri dari psikiater dan psikolog. Data yang dikumpulkan adalah data demografi dan kondisi depresi menggunakan kuesioner Beck Depression Inventory (BDI).
\end{abstract}

\footnotetext{
1,2 Departemen/SMF Jiwa Fakultas Kedokteran Universitas Gadjah Mada

${ }^{3,4}$ Departemen/SMF Obsgin Fakultas Kedokteran Universitas Gadjah Mada
} 
Hasil dan Pembahasan: Sebanyak 59,3\% subyek dalam kondisi depresi ringan, sedangkan 40,63\% dalam kondisi depresi sedang. Terdapat perubahan kondisi depresi secara signifikan pada kelompok intervensi.

Kesimpulan: Modifikasi psikoterapi suportif dapat menurunkan secara efektif depresi pada wanita infertil.

Kata kunci: Modifikasi psikoterapi suportif pendek, depresi, wanita infertil

\section{PENDAHULUAN}

Kesehatan reproduksi menjadi perhatian publik sejak diangkatnya isu tersebut dalam International Conference on Population and Development (ICPD) pada 1994 di Kairo, Mesir. Konferensi tersebut menghasilkan kesepakatan bersama mengenai definisi kesehatan reproduksi sebagai kesehatan secara fisik, mental, dan kesejahteraan sosial secara utuh pada semua hal yang berhubungan dengan sistem dan fungsi serta proses reproduksi, bukan hanya kondisi bebas dari penyakit atau kecacatan. ${ }^{1}$

Sekitar $85-90 \%$ pasangan usia produktif yang sehat, kemungkinan untuk hamil dalam waktu 1 tahun, sebagian besar dalam 6 bulan. Infertilitas mempengaruhi sekitar $10-15 \%$ dari pasangan dan merupakan bagian penting bagi dokter. ${ }^{1}$

Penelitian yang melaporkan prevalensi infertilitas di negara-negara berkembang sangat terbatas. Angka prevalensi infertil dalam 12 bulan berkisar antara 6,9-9,3\% di negara berkembang ${ }^{2}$. Data WHO menyebutkan persentase wanita usia 15-49 tahun yang mengalami infertilitas primer di Indonesia yaitu usia 15 - 19 tahun sebanyak 4,5\%; usia 20 - 24 tahun 21,3\%; usia $25-29$ tahun 16,8\%; usia 30 - 34 tahun 4,9\%; $35-39$ tahun 8,$25 ; 40-44$ tahun $3.3 \%$ dan usia $45-49$ tahun sebanyak $3.5 \%{ }^{3}$

Angka prevalensi infertil dalam 12 bulan berkisar antara 6,9 - 9,3\% di negara berkembang. Prevalensi infertilitas dipengaruhi oleh perbedaan geografis, dan perbedaan ini sebagian besar dijelaskan oleh karena pengaruh lingkungan, budaya dan sosial ekonomi yang berbeda.
Prevalensi infertil di daerah gurun Sahara yaitu 9\% di Gambia dan 11,8\% di Ghana dibandingkan dengan $21,2 \%$ di barat laut Ethiopia dan antara 20 dan 30\% di Nigeria. ${ }^{4}$ Orang Indonesia tak luput dari permasalahan mengenai infertilitas pasangan suami istri. Prevalensi infertil primer di Indonesia tahun 1991 sebesar 2,6\%; tahun 1994 sebesar 2,1\%; tahun 1997 dan 2002 sebesar $2,6 \%$; sedangkan pada tahun 2007 sebesar $2,5 \%{ }^{5}$

Beberapa penelitian telah melaporkan adanya gangguan suasana perasaan, cemas dan depresi, serta kepuasan yang lebih rendah dengan pernikahan mereka dan kehidupan seksual, di antara suami. Prevalensi depresi adalah sekitar $30 \%-40 \%$ di antara perempuan pasangan infertil, dan perbandingan angka kejadian gangguan psikiatri pada perempuan sebanyak $61,1 \%$ dan $21 \%$ pada laki-laki. Perempuan berada pada risiko yang lebih tinggi mengalami tekanan emosional bahkan selama pengobatan, dan terutama ketika penyebab infertilitas diidentifikasi terjadi pada istri atau ketika siklus berulang pengobatan diulang. Harga diri rendah dan rasa bersalah / menyalahkan juga dilaporkan sebagai lebih tinggi di antara perempuan dibandingkan lakilaki. ${ }^{6}$ Dukungan psikoterapi dikatakan mapu membantu mengurangi masalah depresi.

Berdasarkan uraian tersebut di atas maka penelitian ini bertujuan untuk mengukur keberhasilan psikoterapi suportif dalam mengurangi depresi pada wanita infertil yang berobat di Klinik Permata Hati RSUP Dr Sardjito Yogyakarta. 


\section{METODE}

Subyek penelitian pada penelitian ini adalah wanita infertil yang berobat di klinik Permata Hati RSUP Dr.Sardjito dari bulan April 2104 sampai September 2014. Infertilitas didefinisikan sebagai kegagalan untuk mencapai kehamilan yang sehat setelah 12 bulan atau lebih, melakukan hubungan seks tanpa alat kontrasepsi atau terapi inseminasi donor. ${ }^{7}$

Responden penelitian ada 80 wanita infertil, dinilai depresi dengan menggunakan Beck Depression Inventory (BDI).

BDI merupakan instrument self-report yang dirancang untuk menilai intensitas depresi pada pasien psikiatri, skrining di dalam komunitas maupun untuk penelitian klinik dengan nilai sensitivitas $83 \%$ dan spesifisitas $82 \%$. BDI terdiri dari 21 pertanyaan yang mengevaluasi gejalagejala depresi, diberiskala0-3, dengan nilai maksimal adalah 63 dan minimal adalah 0 . Penilaian skala pengukuran BDI: 0-9: normal, 1015: depresi ringan, 16-29: depresi sedang, $\geq 30$ : depresi berat. $^{8}$

Responden dilakukan pre-test BDI dan dilakukan wawancara mendalam mengenai keadaan dan perasaan selama mengikuti terapi infertilitas. Sesudah dilakukan pre-test, responden dibagi dalam dua kelompok. Kelompok perlakuan mengikuti psikoterapi suportif Kelompok kontrol tidak dilakukan intervensi apapun, kemudian dilakukan post-test setelah 1 bulan. Sedangkan pada kelompok intervensi dilakukan post-test setelah psikoterapi selesai dilakukan.

Psikoterapi suportif dilakukan oleh seorang psikiater dan dua psikolog yang telah dilatih mengenai modul intervensi psikoterapi suportif. Intervensi psikoterapi suportif dilakukan satu minggu sekali selama empat minggu kepada subyek secara berkelompok. Sesi psikoterapi suportif dilakukan di unit kontrasepsi RSUP
Dr.Sardjito. Setiap sesi berlangsung selama dua sampai tiga jam yang meliputi ventilasi, persuasi, reassurance, sugestif, bimbingan dan penyuluhan. Penyuluhan mengenai definisi stres dan depresi, mekanisme coping, dan komunikasi asertif yang sebaiknya dilakukan dalam menjalani masalah.

Pada penelitian ini uji statistik untuk mengetahui perbedaan nilai skor BDI dilakukan menggunakan program SPSS versi 17 (Statistical Product for Service Solution) versi 17.

\section{HASIL DAN PEMBAHASAN}

Keseluruhan responden yang mengikuti penelitian ada 70 wanita infertil, terdapat sebanyak 33 responden mengalami depresi $(47,14 \%)$. Kelompok kontrol sebanyak 21 responden dan kelompok perlakuan 12 responden. Pada proses penelitian ada 1 orang peserta kelompok intervensi yang drop out, karena tidak bisa mengikuti minimal 3 sesi psikoterapi.

Mayoritas wanita infertil yang mengalami depresi pada penelitian ini berusia antara 25 35 tahun (81,25\%). Pada penelitian ini wanita infertil yang menjalani terapi di klinik permata hati masih dalam masa usia subur. Pendidikan terakhir terbanyak dari wanita infertil yang ikut serta dalam penelitian adalah S1(59,37\%). Sebagian besar wanita infertil bekerja swasta $(40,62 \%)$, pekerjaan mereka antara lain sebagai notaris, konsultan, pedagang maupun karyawan. Wanita infertil terbanyak telah melangsungkan pernikahan selama 7 - 9 tahun $(46,87 \%)$ dan lama mengikuti program infertilitas di klinik Permata Hati selama 1 bulan - 1 tahun (53,13\%).

Ketidakmampuan memiliki anak adalah hal yang sangat mengecewakan bagi pasangan yang bisa mengarah ke gangguan psikologis seperti depresi. ${ }^{9}$ Hasil penelitian menunjukkan bahwa pada kelompok intervensi, depresi pada 
posttest dibandingkan dengan pretest secara signifikan lebih rendah $(P<0,003)$. Penurunan depresi juga signifikan pada kelompok kontrol ( $P$ $=0,003)$. Selain itu, kebahagiaan menunjukkan peningkatan yang signifikan pada kelompok intervensi ketika hasil post-test dan pre-test dibandingkan, Namun, peningkatan ini tidak signifikan pada kelompok kontrol. ${ }^{10}$

Tabel 1. Perbandingan Karakteristik Wanita Infertil yang Mengalami Depresi

\begin{tabular}{|c|c|c|c|c|c|c|c|}
\hline \multirow{2}{*}{ Variabel } & \multicolumn{3}{|c|}{ Perlakuan } & \multicolumn{3}{|c|}{ Kontrol } & \multirow[b]{2}{*}{$\mathrm{p}$} \\
\hline & $\mathrm{n}$ & $\%$ & Mean \pm SD & $\mathrm{n}$ & $\%$ & Mean \pm SD & \\
\hline \multicolumn{8}{|l|}{ Usia } \\
\hline$\geq 35$ tahun & 5 & 45,5 & & 9 & 42,9 & & 0.888 \\
\hline$<35$ tahun & 6 & 54,5 & & 12 & 57,1 & & \\
\hline \multicolumn{8}{|l|}{ Suku bangsa } \\
\hline Jawa & 6 & 54,5 & & 20 & 95,2 & & 0,005 \\
\hline Non Jawa & 5 & 45,5 & & 1 & 4,8 & & \\
\hline \multicolumn{8}{|l|}{ Pendidikan } \\
\hline Menengah & 2 & 18,2 & & 6 & 28,6 & & 0,519 \\
\hline Tinggi & 9 & 81,8 & & 15 & 71,4 & & \\
\hline \multicolumn{8}{|l|}{ Pekerjaan } \\
\hline PNS & 3 & 27,3 & & 5 & 23,8 & & 0,937 \\
\hline Swasta & 5 & 45,4 & & 9 & 42,9 & & \\
\hline Tidak bekerja & 3 & 27,3 & & 7 & 33,3 & & \\
\hline \multicolumn{8}{|l|}{ Lama Menikah } \\
\hline 1-2 tahun & 2 & 18,2 & & 9 & 42,9 & & 0,163 \\
\hline$>2$ tahun & 9 & 81,8 & & 12 & 57,1 & & \\
\hline \multicolumn{8}{|c|}{ Lama mengikuti program } \\
\hline$\leq 1$ tahun & 6 & 54,6 & & 16 & 76,2 & & 0,210 \\
\hline$>1$ tahun & 5 & 45,4 & & 5 & 23,8 & & \\
\hline \multicolumn{8}{|c|}{ Frekuensi mengikuti program } \\
\hline $1-3$ & 10 & 90,9 & & 21 & 100 & & 0,160 \\
\hline 4-6 & 1 & 9,1 & & 0 & 0,00 & & \\
\hline \multicolumn{8}{|l|}{$\begin{array}{l}\text { Keluarga tinggal } 1 \\
\text { rumah }\end{array}$} \\
\hline Ada & 4 & 36,4 & & 9 & 42,9 & & 0,722 \\
\hline Tidak & 7 & 63,6 & & 12 & 57,1 & & \\
\hline \multicolumn{8}{|c|}{ Suami tinggal dalam 1 kota } \\
\hline Ya & 7 & 63,6 & & 19 & 90,5 & & 0,065 \\
\hline Tidak & 4 & 36,4 & & 2 & 9,5 & & \\
\hline \multicolumn{8}{|c|}{ Lingkungan tempat tinggal } \\
\hline Perkotaan & 3 & 27,3 & & 7 & 33,33 & & 0,725 \\
\hline Pedesaan & 8 & 72,7 & & 14 & 66,7 & & \\
\hline
\end{tabular}




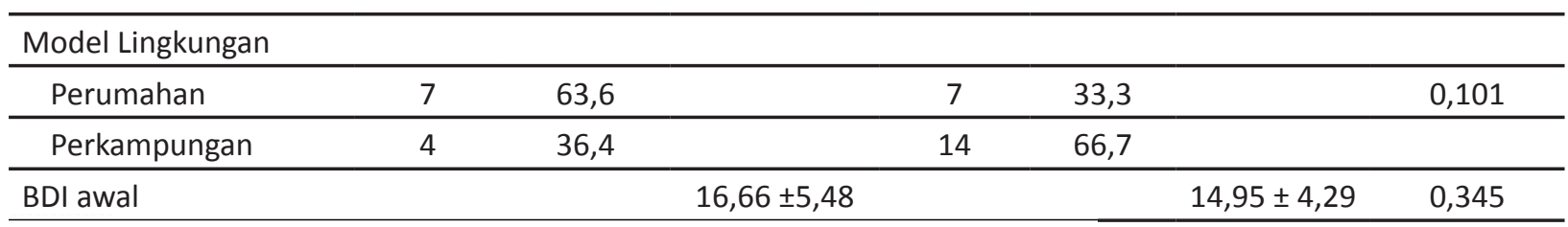

Sumber : Data Primer

Tabel 1 menunjukkan bahwa suku asal wanita infertil yang mengalami depresi berhubung signifikan dengan perubahan nilai skor BDI pada pre-test maupun post-test, hal ini signifikan ( $p=$ $0,005)$.

$$
\begin{aligned}
& \text { Pernyataan yang mengikuti psikoterapi } \\
& \text { suportif mengenai perilaku keluarga suami } \\
& \text { terutama ibu mertua yang tinggal bersama } \\
& \text { selama } 8 \text { tahun: } \\
& \text { "Saya merasa tidak nyaman dengan perilaku } \\
& \text { simbok yang sering membuat saya tidak } \\
& \text { nyaman dan ingin pulang saja tinggal dengan } \\
& \text { orang tua saya. Simbok sering melempar } \\
& \text { barang atau marah tidak jelas bila ada hal } \\
& \text { yang tidak sesuai dengan kemauannya". }
\end{aligned}
$$

Pada saat yang sama peserta yang lain juga menjelaskan bagaimana tidak nyamannya tinggal bersama dengan mertua selama 8 bulan:

" Mertua saya, terutama ibu mertua selalu menyindir saya kenapa setelah menikah selama 3 tahun bulan juga mempunyai anak, dan selalu menyalahkan saya, bahwa sayalah yang bermasalah sehingga sulit mempunyai anak. Hal tidak menyenangkan tersebut sedikit berubah setelah mengetahui bahwa suami saya mempunyai varikokel yang menyebabkan kami belum mempunyai momongan. Setelah saya pindah ke rumah sendiri, saya selalu menangis dan bertengkar dengan suami bila akan berkunjung ke rumah mertua".

Tabel 2. Beda Rerata Skor BDI Awal dan Akhir antara Kelompok perlakuan dan kontrol pada wanita infertil yang mengalami depresi.

\begin{tabular}{ccccccccc}
\hline & \multirow{2}{*}{$\mathrm{n}$} & \multicolumn{2}{c}{ BDI1 } & \multicolumn{2}{c}{ BDI1 } & $\mathrm{p}$ & \multirow{2}{*}{ Mean } & \multicolumn{1}{c}{ Cl95\% } \\
\cline { 2 - 6 } & & Mean & SD & Mean & SD & & & \\
\hline Perlakuan & 11 & 16,63 & 5,48 & 7,27 & 3,19 & 0,001 & 9,36 & $5,19-13,52$ \\
\hline Kontrol & 21 & 14,95 & 4,29 & 14,71 & 3,42 & 0,77 & 0,24 & $-1,48-1,95$ \\
\hline
\end{tabular}

Sumber: Data primer

Pada tabel 2 menunjukkan beda rerata skor Beck Depression Inventory (BDI) sebelum (pretest) (BDI1) dan sesudah/post-test (BDI2) pada kelompok kontrol maupun kelompok perlakuan setelah intervensi psikoterapi suportif. Terdapat perbedaan bermakna pada skor BDI akhir pada kelompok intervensi $(\mathrm{p}=0,01 ; 95 \% \mathrm{Cl}=5,19-$ 13,52). Hal ini menunjukkan bahwa intervensi kelompok dalam psikoterapi suportif pada kelompok perlakuan menurunkan skor depresi pada wanita infertil. 
Tabel 3. Pengaruh peran intervensi terhadap perubahan rerata skor BDI setelah dikontrol variabel pendidikan dan lama menikah

\begin{tabular}{|c|c|c|c|c|}
\hline & $\begin{array}{l}\text { Model } 1 \\
\text { P value } \\
\text { Koef } \\
\text { Cl } 95 \% \\
\end{array}$ & $\begin{array}{l}\text { Model } 2 \\
\text { P value } \\
\text { Koef } \\
\text { Cl 95\% } \\
\end{array}$ & $\begin{array}{l}\text { Model } 3 \\
\text { P value } \\
\text { Koef } \\
\text { Cl } 95 \% \\
\end{array}$ & $\begin{array}{l}\text { Model } 3 \\
\text { P value } \\
\text { Koef } \\
\text { Cl } 95 \% \\
\end{array}$ \\
\hline \multicolumn{5}{|c|}{$\begin{array}{l}\text { Peran interven- } \\
\text { si psikoterapi } \\
\text { suportif }\end{array}$} \\
\hline \multirow[t]{3}{*}{ Perlakuan } & 0,001 & 0,001 & 0,001 & 0,001 \\
\hline & $-9,12$ & $-8,68$ & $-8,22$ & $-7,79$ \\
\hline & $-12,71--5,3$ & $-12,06--5,30$ & $-11,73--4,71$ & $-11,04--4,53$ \\
\hline \multicolumn{5}{|l|}{ Kontrol } \\
\hline \multicolumn{5}{|l|}{ Pendidikan } \\
\hline \multirow[t]{3}{*}{ - Menengah } & & 0,026 & & 0,019 \\
\hline & & $-4,25$ & & $-4,21$ \\
\hline & & $-7,95-0,54$ & & $-7,67--0,74$ \\
\hline \multicolumn{5}{|l|}{ Tinggi } \\
\hline \multicolumn{5}{|c|}{ Lama menikah } \\
\hline \multirow[t]{3}{*}{ 1-2 tahun } & & & 0,041 & 0,029 \\
\hline & & & $-3,67$ & $-3,63$ \\
\hline & & & $-7,17--0,5$ & $-6,86--0,39$ \\
\hline \multicolumn{5}{|l|}{$>2$ tahun } \\
\hline $\mathrm{R} 2$ & 0,47 & 0,56 & 0,54 & 0,63 \\
\hline Constanta & 0,23 & 2,79 & 1,85 & 4,84 \\
\hline$N$ & 32 & 32 & 32 & 32 \\
\hline
\end{tabular}

Sumber : data primer

Tabel 3 menentukan efektivitas intervensi psikoterapi suportif dalam menurunkan depresi pada wanita infertil, dianalisis menggunakan regresi linear metode Backward untuk mengidentifikasi variabel yang berpengaruh terhadap penurunan skor BDI. Variabel pendidikan, lama menikah dan intervensi psikoterapi suportif yang dilakukan.

Merupakan predicator penurunan skor depresi wanita hamil. Satu orang wanita yang mengikuti psikoterapi suportif berhasil hamil.
Ketidakmampuanuntuk memiliki anak menjadi pengalaman menyedihkan baik pada pria maupun wanita yang dapat menyebabkan gangguan psikologis besar seperti depresi. Depresi dikatakan menjadi masalah utama yang terkait dengan infertilitas terutama di Afrika di mana anakanak sangat dihargai untuk alasan sosial budaya dan ekonomi. ${ }^{9}$ Mayoritas wanita infertil yang mengalami depresi pada penelitian ini berusia antara 25 - 35 tahun (81,25\%). Pada penelitian ini wanita infertil yang menjalani terapi di klinik permata hati masih dalam masa usia subur. 
Infertilitas adalah peristiwa stres dalam kehidupan manusia. Dibandingkan dengan pasien dengan kondisi medis lainnya, gejala psikologis yang terkait dengan infertilitas adalah sama dengan pasien kanker, hipertensi dan rehabilitasi jantung. ${ }^{11}$ Pria maupun wanita yang mengalami stres dari waktu ke waktu, ketegangan pada tubuh dari stres rutin dapat menyebabkan masalah serius kesehatan, serta depresi dan gangguan kecemasan. ${ }^{12}$

Ketidakmampuan memiliki anak adalah hal yang sangat mengecewakan bagi pasangan yang bisa mengarah ke gangguan psikologis seperti depresi. ${ }^{9}$ Keseluruhan karakteriristik pada wanita infertil yang mengalami depresi setelah dianalisis antara kelompok kontrol dan kelompok perlakuan, ditemukan perbedaan bermakna pada tingkat pendidikan dan lamanya menikah $(p<0,05)$.

Infertilitas merupakan tanggung jawab sosial bagi perempuan di Arab Saudi, memiliki anak menjadi sebuah harapan sejak dini dalam kehidupan perkawinan mereka. Perempuan tanpa anak-anak sering merasa tidak lengkap dan mengalami tekanan dari keluarga dan masyarakat mereka, sehingga berisiko memiliki masalah psikologis. Depresi dinilai dari skor depresi dari BDI pada wanita infertil yang memiliki tekanan dari keluarga karena belum hamil lebih tinggi dibandingkan pada wanita yang tidak memiliki tekanan dan secara statistik signifikan. ${ }^{13}$

Keluarga menjadi salah satu stresor munculnya depresi pada wanita infertil. Keluarga yang tinggal dalam satu rumah dengan wanita infertil, terbanyak adalah ibu mertua (43\%), kemudian orang tua kandung (29\%), dan keluarga lainnya seperti nenek, adik kandung, sepupu dan keponakan (7\%). Keluarga yang tinggal dalam satu rumah dapat menjadi stressor yang menyebabkan terjadi depresi maupun memperberat depresi yang sudah dialami oleh wanita. Keluarga yang terbanyak menjadi stressor adalah mertua (86\%), terutama ibu mertua. Tingkat depresi secara signifikan lebih tinggi pada responden yang mengalami stressor berat.$^{14}$

Intervensi dan sikap negatif dari kerabat terutama keluarga suami dan lingkungan (keluarga, teman, tetangga) menyebabkan masalah psikologis bagi wanita infertil. Umumnya wanita infertil mengalami konsekuensi sosial yang negatif termasuk ketidakharmonisan perkawinan, stigmatisasi dan perlakuan yang tidak baik. Infertilitas dapat menyebabkan gangguan psikologis yang mengganggu kesejahteraan dan status sosial perempuan di Iran. ${ }^{6}$

Tingginya angka kejadian depresi pada wanita infertil menunjukkan perlunya intervensi psikologis. Terlepas dari kenyataan bahwa tidak ada penelitian yang dilakukan tentang efek infertilitas pada kebahagiaan wanita yang mengikuti program infertilitas, namun kebahagiaan bisa terancam ketika wanita infertil mengalami depresi. Salah satu alasan yang menghalangi kebahagiaan disebabkan oleh tingginya biaya pengobatan infertilitas, khususnya di Iran, karena penelitian telah menunjukkan bahwa tingkat kebahagiaan dikaitkan dengan pendapatan absolut dan relatif dari individu. ${ }^{15}$

\section{KESIMPULAN DAN SARAN}

Psikoterapi suportif pada wanita infertil yang mengalami depresi dapat menurunkan depresi yang dinilai dengan pengaruh intervensi psikoterapi suportif pada wanita infertil yang mengalami depresi pada kelompok perlakuan dapat menurunkan skor depresi dibandingkan pada kelompok kontrol yang tidak mengiikuti psikoterapi suportif. Estimasi psikoterapi suportif, pendidikan dan lama menikah merupakan predicator penurunan skor depresi pada wanita infertil. 
Hasil penelitian disarankan kepada dokter spesialis obstetri dan ginekologi di klinik Permata Hati untuk melibatkan psikiater dalam penatalaksanaan program infertilitas. Penelitian yang dilakukan ini dan beberapa penelitian sebelumnya telah menjelaskan peran psikoterapi suportif. dalam meningkatkan keberhasilan program infertilitas dan meningkatkan kehamilan pada wanita infertil.

\section{DAFTAR PUSTAKA}

1. Sadli S, Rahman A, Habsjah A. Implementasi Pasal 12 UU nO 7 Tahun 1984: Pelayanan Kehamilan dan Pasca Kehamilan. Jakarta, Indonesia, Universitas Indonesia; 2006.

2. Boivin J, Bunting L, Collins JA, Nygren KG. International estimates of infertility prevalence and treatment-seeking: potential need and demand for infertility medical care. Human Reproduction. 2007;22:1506-1512.

3. WHO. Infecundity, Infertility, and Childlessness in Developing Countries, DHS Comparative Reports No.9, 2004.

4. Ombelet W, Cooke I, Dyer S, Serour G, Devroey $P$. Infertility and the provision of infertility medical services in developing countries. Human Reproduction Update. 2008;14(6): 605-621.

5. Mascarenhas $M N$, Cheung $H$, Mathers $C D$, Steven GA. Measuring infertility in populations: constructing a standard definition for use with demographic and reproductive health surveys. Population Health Metrics. 2012;10(17).

6. Ramezanzadeh F, Aghssa M, Abedinia N, Zayeri F, Khanafshar N, Shariat $M$, et al. A survey of relationship between anxiety, depression and duration of infertility. BMC Women s Health. 2004 2004/11/06;4(1):1-7.
7. Medicine PCotASfR. Definitions of infertility and recurrent pregnancy loss: a committee opinion. Fertility and Sterility. 2013;99(1):63

8. Rutstein SO, Shah $\mathrm{IH}$. Infecundity infertility and childlessness in developing countries. 2004.

9. Alhassan A, Ziblim RA, Muntaka S, A survey on depression among infertile woman in Ghana. BMC Women"s Health, 2014 14(42): 1-6.

10. Asl STS, Sadeghi K, Bakhtiari M, Ahmadi MS, Anamagh NA, Khayatan T. The Effectiveness of Group Positive Psychotherapy on Improving the Depression and Increasing the Happiness of the Infertile Women : Clinical Trial. Euro.J.Exp.Bio, 2014, 4(3):269-275.

11. Khademi A, Alleyassin A, Aghahosseini M, Ramezanzadeh F, Abhari AA. Pretreatment Beck Depression Inventory score is an important predictor for Post-treatment score in infertile patients : a before - after study. BMC Psychiatri, 2005; 5: 1-7.

12. Infertility, National Institute of Health, 2009.

13. Al-Homaidan HT. Depression among Women with Primary Infertility attending an Infertility Clinic in Riyadh, Kingdom of Saudi Arabia: Rate, Severity, and Contributing Factors. International journal of health sciences. 2011;5(2):108.

14. Noorbala AA, Ramazanzadeh F, Malekafzali $H$, Abedinia N, Forooshani AR, Shariat M, et al. Effects of a psychological intervention on depression in infertile couples. International Journal of Gynecology \& Obstetrics, 2008;101(3):248-52.

15. Ball R, Chernova K. Absolute Income, Relative Income, and Happiness. Soc Indi Res, 2008; 88(3): 497-529.

16. Fritz MA, Speroff L. Clinical Gynecologic Endocrinology and Infertility: Lippincott Williams \& Wilkins, 2012. 